\title{
Cardioprotection by regular ethanol consumption: potential mechanisms and clinical application.
}

\author{
Masami Miyamae \\ Osaka Dental University, Osaka, Japan \\ Kazuhiro Kaneda \\ Osaka Dental University, Osaka, Japan \\ Naochika Domae \\ Osaka Dental University, Osaka, Japan \\ Vincent M. Figueredo, M.D. \\ Thomas Jefferson University \\ Follow this and additional works at: https://jdc.jefferson.edu/cardiologyfp \\ Part of the Cardiology Commons \\ Let us know how access to this document benefits you
}

\section{Recommended Citation}

Miyamae, Masami; Kaneda, Kazuhiro; Domae, Naochika; and Figueredo, M.D., Vincent M., "Cardioprotection by regular ethanol consumption: potential mechanisms and clinical application." (2010). Division of Cardiology Faculty Papers. Paper 15.

https://jdc.jefferson.edu/cardiologyfp/15

This Article is brought to you for free and open access by the Jefferson Digital Commons. The Jefferson Digital Commons is a service of Thomas Jefferson University's Center for Teaching and Learning (CTL). The Commons is a showcase for Jefferson books and journals, peer-reviewed scholarly publications, unique historical collections from the University archives, and teaching tools. The Jefferson Digital Commons allows researchers and interested readers anywhere in the world to learn about and keep up to date with Jefferson scholarship. This article has been accepted for inclusion in Division of Cardiology Faculty Papers by an authorized administrator of the Jefferson Digital Commons. For more information, please contact: JeffersonDigitalCommons@jefferson.edu. 


\author{
As submitted to: \\ Current Drug Abuse Reviews \\ And later published as: \\ Cardioprotection by Regular Ethanol Consumption: \\ Potential Mechanisms and Clinical Application \\ Volume 3, Issue 1, 2010, Pages 39-48 \\ PubMed ID: 20230376
}

Masami Miyamae*, Kazuhiro Kaneda\#, Naochika Domae*, and Vincent M. Figueredo

*Department of Internal Medicine, Osaka Dental University, Osaka, Japan

\#Department of Anesthesiology, Osaka Dental University, Osaka, Japan

IInstitute for Heart and Vascular Health, Albert Einstein Medical Center, and Jefferson Medical College, Philadelphia, USA

Conflict of Interest: The authors have no conflicts of interest to report. 
Key Words: ethanol, ischemia-reperfusion injury, preconditioning, heart

Corresponding Author \& Reprints: Masami Miyamae, MD, PhD

Department of Internal Medicine,

Osaka Dental University

8-1 Kuzuha hanazono-cho Hirakata,

Osaka 573-1121, Japan

TEL : 81-72-864-3079, FAX : 81-72-864-3179

E-mail: miyamae0907@gmail.com

Running Title: ethanol in cardiac ischemia-reperfusion injury 


\begin{abstract}
Epidemiological studies demonstrate that excessive drinking is associated with hypertension, cerebral bleeding and loss of cardiac contractility. Conversely, studies have shown that mortality rates for people who regularly drink ethanol in moderation are lower than in abstainers, primarily due to decreased fatal ischemic heart disease. Further, moderate ethanol consumers have lower rates of myocardial infarction compared with abstainers. These beneficial cardiac effects may be due to pleiotropic effects of ethanol on lipids, platelets, and fibrinolytic activity. During the past decade, studies conducted in several animal models have revealed that light to moderate regular ethanol consumption renders hearts more tolerant to myocardial ischemia-reperfusion injury; to a degree similar to cardiac ischemic preconditioning (brief episodes of ischemia dramatically limit infarct size following prolonged ischemia). Recent clinical evidence suggests that light to moderate ethanol consumption in the year prior to myocardial infarction is associated with reduced mortality following myocardial infarction. These findings suggest that light to moderate ethanol consumption not only prevents myocardial infarction but also improves survival after myocardial infarction. Proposed mechanisms of cardioprotection by regular ethanol consumption include activation of adenosine A1 receptors, $\alpha_{1}$-adrenoceptors, protein kinase C- $\delta$ and $\varepsilon$, adenosine triphosphate-dependent potassium ( $\left.\mathrm{K}_{\text {ATP }}\right)$ channels, nitric oxide synthase and reduced leukocyte-endothelial cell adhesive interactions. In this review, we focus on the recent progress in elucidating the endogenous myocyte signaling mediating cardioprotection by light to moderate ethanol consumption.
\end{abstract}




\section{INTRODUCTION}

The link between ethanol and cardiovascular disease is important because diseases affecting the circulatory system are a leading cause of mortality in many developing countries. Numerous studies have demonstrated that excessive drinking is associated with cardiovascular disorders, including cardiomyopathy, hypertension, arrhythmia, coronary heart disease, cerebral bleeding and other life-threatening medical complications [1-3]. Especially, ischemic heart disease is most important all over the world. Since ancient times, however, it has long been recognized that ethanol in moderation is healthy; ethanol abuse detrimental. In the past century, epidemiological studies have shown that mortality rates for people who regularly drink ethanol in moderation are lower than in abstainers $[1,2,4,5]$. This is primarily due to decreased incidence of fatal ischemic heart disease $[6,7]$. The beneficial cardiac effects of moderate ethanol consumption may be due to the pleiotropic effects of ethanol on lipids [8], platelets, and fibrinolytic activity [9,10]. Even very low consumption of ethanol (one or two drinks per week) has been shown to be cardioprotective [11].

Recent clinical studies demonstrated that light to moderate ethanol consumption may provide further cardioprotection, attenuating ischemia-reperfusion injury and improving outcome after acute myocardial infarction [12-16]. Moderate ethanol consumers improved survival after myocardial infarction compared with abstainers [13]. During the past decade, studies conducted in several animal models have revealed that light to moderate regular ethanol consumption renders hearts more tolerant to myocardial ischemia-reperfusion injury to a degree similar to cardiac ischemic preconditioning $[17,18]$, in which brief episodes of ischemia and reperfusion dramatically limit infarct size following prolonged ischemia [19]. 
We have termed this protective effect of ethanol against ischemia-reperfusion injury "ethanol preconditioning" [17].

Recognizing the deleterious effects of ethanol abuse on the heart and other organ systems, in this review, we discuss two potential beneficial effects of light to moderate ethanol consumption on the heart; prevention of coronary heart disease and reduction of ischemia-reperfusion injury. We review pleiotropic effects of ethanol which may contribute to decreased development of ischemic heart disease. We then discuss the endogenous myocyte signaling likely mediating ethanol cardioprotection against ischemia-reperfusion injury.

\section{Pleiotropic Effects of Ethanol: prevention of ischemic heart disease}

Clinical and epidemiologic studies show that moderate drinkers have less cardiovascular disease when compared with nondrinkers or heavy drinkers [1-3,20,21]. This is primarily due to a decreased incidence of coronary heart disease which results in a U-shaped or Jshaped curve between ethanol consumption and mortality. Plausible mechanisms for this cardioprotection, as well as adverse effects of ethanol abuse, are shown in Figure 1. These mechanisms include increases in high density lipoprotein cholesterol (HDL-C), decreases in low density lipoprotein cholesterol (LDL-C) [22], decreased platelet aggregation, increased fibrinolytic activity, suppression of inflammatory cytokines and increased insulin sensitivity through increased levels of plasma adiponectin [23]. Ethanol consumption increases apolipoprotein A-I and A-II which are the main protein components of HDL-C [24]. Multiple 
epidemiological studies have shown an inverse relationship between serum HDL-C (especially HDL3) level and morbidity due to ischemic heart disease $[8,20,24-26]$. Rimm at al., calculated that consumption of $30 \mathrm{~g}$ ethanol per day, regardless of beverage type, reduces ischemic heart disease events $16.8 \%$ by increasing HDL-C [20]. Reports suggest that at least half of the beneficial effect of ethanol on atherosclerosis is attributed to increased HDL $[27,28]$.

Rao et al. demonstrated that light, but not heavy, ethanol consumption upregulates paraoxonase 1 expression [32]. Increased serum paraoxonase has been shown to limit LDL-C peroxidation and play a major role in the protective effect of HDL against coronary artery disease $[33,34]$. Ethanol induces qualitative changes on HDL-C which results in phospholipids enrichment. This is thought to reduce the inflammatory response of atherogenesis [35]. Anti-inflammatory effects by moderate ethanol consumption are well established. Imhof et al., studied a random cross-sectional sample of over 8000 men and women in three European countries to investigate the effect of ethanol consumption on inflammatory markers including white blood cell counts, fibrinogen and C-reactive protein (CRP). Moderate ethanol consumers was associated with lower levels of these markers [36].

Moderate ethanol consumption may have beneficial effects on the vascular system, reducing CRP and adhesion molecules, including intercellular adhesion molecule (ICAM), vascular cell adhesion molecule (VCAM) and E-secletin [37,38]. Pai et al., studied over 
1400 healthy men and women from a large prospective study. They found significant trends between increasing ethanol intake and soluble tumor necrosis factor- $\alpha$ (TNF- $\alpha$ ) receptor 1 and 2 . Compared with abstainers, men who consumed on average 1-2 drinks/day had $26 \%$ lower CRP and 36\% lower interleukin-6, a proinflammatory cytokine. A similar association was observed in women who consumed half drink per day [39].

Other proposed mechanisms for the protective effect of moderate ethanol consumption against ischemic heart disease events include beneficial effects on hemostasis [40], endothelial function and insulin resistance [41]. Moderate ethanol consumption has been shown to affect several hemostatic factors, including fibrinogen concentration, platelet aggregability, tissue plasminogen activator (t-PA) and plasminogen activator inhibitor [20,42-44]. Moderate ethanol consumption decreases platelet aggregation, increases fibrinolytic activity and reduces fibrinogen levels, as well as levels of the Von Willebrand factor, important in platelet adhesion and aggregation [45]. Endothelial cells also have been reported to play an important role in increased fibrinolytic activity induced by ethanol consumption [46]. Booyse et al., demonstrated that fibrinolytic protein such as t-PA expression is modulated by ethanol and wine polyphenols. Clot lytic rates significantly increased in mice treated with either ethanol, catechins and quercetin [30]. Nitric oxide (NO) produced from endothelial cell inhibits smooth muscle cell proliferation and platelet aggregation [47].

Furuya et al. demonstrated that there is an inverted U-shaped relationship between ethanol intake and insulin sensitivity in an experimental model [49]. Bell et al., assessed the relationships between ethanol consumption and insulin sensitivity and coronary risk factors in a cross-sectional analysis of 1,196 subjects. They found that moderate ethanol 
consumption was associated with improved insulin sensitivity and modifiable cardiac risk factors such as lipids and blood pressure [41].

When considering the relationship between ethanol consumption and coronary heart disease, the role of confounding variables such as diet, physical activity and genetics cannot be ignored. Light to moderate ethanol consumption is associated with a lower prevalence of metabolic syndrome, with beneficial effects on lipids, waist circumference and fasting insulin [50]. Studies suggest that wine consumption is associated with a diet high in fruits, vegetables and fish and low in saturated fat (Mediterranean diet) [51,52] [53]. It has been demonstrated that the mortality of fatal ischemic disease is lower among the physically active who consume moderate ethanol [54].

Genetic differences may also contribute to the variability in metabolic capacity of ethanol among individuals. This may in turn influence the magnitude of cardioprotection afforded by moderate ethanol consumption. Ethanol is metabolized by alcohol dehydrogenase $(\mathrm{ADH})$ and the mitochondrial form of aldehyde dehydrogenase (ADH2) $[55,56]$ The polymorphism of encoded genes for these enzymes changes their activity and the frequencies of these variants highly depend on the ethnicity.

Finally, non-alcoholic components such as wine polyphenols and dietary isohumulones (the bitter components of beer) have been implicated in the beneficial effects of alcohol beverage on atherosclerosis $[30,31]$. However, it appears that their contribution to cardioprotection is minor comparedto the effects of ethanol. 


\section{Ethanol Preconditioning: attenuating cardiac ischemia-reperfusion injury}

We discovered that regular ethanol consumption renders hearts more tolerant to ischemia-reperfusion injury mimicking cardiac ischemic preconditioning. This protection against ischemia-reperfusion injury is mediated through adenosine $A 1$ receptor activation [17]. In these early studies, guinea pigs were treated with $2.5-20 \%$ ethanol in their drinking water for 3-12 weeks. This corresponds to a range equivalent to mild to heavy ethanol consumption. Isolated hearts were perfused and subjected to $45 \mathrm{~min}$ of no-flow ischemia and 48 min reperfusion. The effect of varying concentrations of ethanol and duration of exposure is shown in Table 1. Treatment for 3 weeks with $10 \%$ ethanol in their drinking water induced cardioprotection. As little as $2.5 \%$ ethanol in the drinking water for 3 weeks protects only against a rise in left ventricular end-diastolic pressure (LVEDP) during reperfusion. However, by 6 weeks of treatment, full protection as indicated by improved left ventricular developed pressure (LVDP) recovery, decrease in LVEDP and creatine kinase release was seen regardless of dose of ethanol. The magnitude of this protection is similar to that of ischemic preconditioning elicited by $2 \mathrm{~min}$ of global ischemia and $5 \mathrm{~min}$ of reperfusion immediately before sustained ischemia in the absence of ethanol (Table 1). These salutary effects of ethanol consumption were abolished by the selective adenosine A1 receptor inhibitor, 8-cyclopentyl-1,3,dipropylxanthine (DPCPX), but not the A2 receptor inhibitor, 3,7-dimethyl-1-propargylxanthine (DNPX). This suggests that the adenosine A1 receptor, but not A2 receptor, plays a crucial role in cardioprotection afforded by chronic ethanol consumption. In another study, we reported that the mechanism of a cardioprotection by regular ethanol consumption can vary by species. In rats, ethanol 
preconditioning was mediated by $\alpha_{1}$-adrenergic signaling, not adenosine A1 receptor signaling[57]. We also demonstrated that chronic ethanol exposure induces sustained translocation of $\varepsilon$-protein kinase $C(P K C)$ in myocytes from the cytosolic to particulate fractions, but not $\alpha-P K C$ and $\delta-P K C$. Isolated myocytes from hearts exposed to ethanol showed immunolocalization of $\varepsilon$-PKC antibody fluorescence from the perinuclear and cytosolic regions to the cross-striations (possibly myofilaments), suggesting that $\varepsilon$-PKC had translocated to activation sites, binding to anchoring molecules (receptors for activated C kinase or RACKs). These data correlated with the data obtained by Western blot analysis [58]. Translocation of PKC has been to play a crucial role in triggering the signal transduction responsible for ischemic preconditioning [59]. Data from most other laboratories corroborate our data (Table 2). Guiraud et al. demonstrated that infarct size of the hearts from rat treated with $7 \%$ ethanol in their drinking water for 7 weeks was smaller than control after 30 min ischemia and 120 min reperfusion [60]. The combination of regular ethanol consumption and ischemia preconditioning further reduced infarct size. However, translocation of $\varepsilon-\mathrm{PKC}$ was not observed in rat myocytes. Pagel et al. employed the method of chronic, intermittent ethanol feeding to more fully mimic the clinical setting. Dogs were fed with ethanol (1.5g/day) mixed with dry food twice per day for 12 weeks. Infarct size of ethanol treated animals was significantly reduced compared with control [61]. Most, but not all, studies show that regular ethanol consumption protects myocardium against ischemiareperfusion injury. Dow et al. failed to demonstrate reductions in myocardial infarct size in rats treated with ethanol (15\% or $36 \%$ in their drinking water) for 16 weeks [62]. Gibson et al. also reported that moderate and heavy amounts of alcohol (defined as $20 \%$ and $35 \%$ of total caloric intake) do not improve, and even worsen functionary recover (increased diastolic stiffness) after $21.5 \mathrm{~min}$ of ischemia followed by $30 \mathrm{~min}$ reperfusion in isolated rat 
hearts [63]. The discrepancy among these studies remains unclear, but might be due to differences in experimental models (Table 2).

\section{Potential Mechanisms of Ethanol Preconditioning}

Numerous studies have been conducted to elucidate the mechanisms of preconditioning induced by regular ethanol consumption against ischemia-reperfusion injury in the past decade. The signal transduction by which regular ethanol consumption exerts a cardioprotective effect against ischemia-reperfusion injury is similar to that of ischemic preconditioning (Figure 2). Adenosine mediates many of the acute and long-term effects of ethanol on cellular and organ functions [64,65]. Ethanol has been shown to increase extracellular adenosine by inhibiting adenosine uptake, which results in activation of adenosine receptors [66]. Experiments in pigs [67], rabbits [68], dogs [69,70], and studies with human tissue [71] indicate that adenosine A1 receptors mediate ischemic preconditioning. Involvement of adenosine A1 receptor activation in cardioprotection by regular ethanol consumption has been demonstrated in guinea pigs [17] and dogs [61], but not in rats [57].

Chronic ethanol exposure in cells with adenosine A1 receptors causes hypersensitization of cAMP production [72], in contrast to cells expressing adenosine A2 receptors where ethanol causes heterologous desensitization of cAMP signal transduction $[73,74]$. In rats, $\alpha_{1}$-adrenergic receptors have been implicated in cardioprotection by regular ethanol consumption [57]. Stimulation of these G-protein coupled receptors by chronic ethanol exposure initiates production of the second messenger diacylglycerol, and results in 
activation of phospholipase C [75] and PKC [58]. PKC signaling is crucial for triggering ethanol preconditioning [76]. Inagaki and Mochly-Rosen demonstrated that activation of $\delta$ PKC induced by acute ethanol exposure mediated $\varepsilon$-PKC activation in ethanol-induced cardioprotection from ischemia [77]. Sustained translocation of $\varepsilon$-PKC from the cytosol to the myocyte membrane [58] or mitochondria [78] has been shown to play a role in ethanol preconditioning. $\varepsilon$-PKC primes both sarcolemmal [79] and mitochondrial [80] adenosine triphosphate-sensitive potassium channels ( sarcK $_{\text {ATP }}$ and mitoK $K_{\text {ATP }}$ ) to open in ischemic preconditioning. Zhu et al. first demonstrated that mitoK $\mathrm{ATP}_{\mathrm{P}}$ channels are required for cardioprotection by chronic ethanol consumption in isolated rat hearts treated with $18 \%$ ethanol for 10 months [81]. Pagel et al. demonstrated that both sarcK $\mathrm{K}_{\mathrm{ATP}}$ and mitoK $_{\text {ATP }}$ play a role in reducing myocardial infarct size by chronic, intermittent ingestion of small amount of ethanol in vivo dog hearts [82].

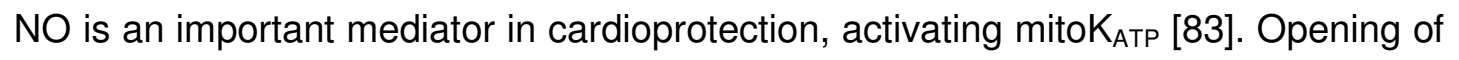
mitoK $_{\text {ATP }}$ increases levels of reactive oxygen species (ROS) in cardiomyocytes [84]. ROS activates a second pool of $\varepsilon$-PKC 1 , designated $\varepsilon$-PKC 2, which inhibits the mitochondrial permeability transition. MitoK $\mathrm{ATP}_{\mathrm{T}}$-generated ROS also activates $\varepsilon$-PKC 1 and induces phosphorylation-dependent mitoK $\mathrm{K}_{\text {ATP }}$ opening. Thus mitoK $\mathrm{K}_{\text {ATP }}$-dependent mitoK $\mathrm{K}_{\text {ATP }}$ opening constitutes a positive feedback loop capable of maintaining the channel open after the stimulus is no longer present. This feedback pathway may be responsible for the lasting protective effect of preconditioning, known as the memory effect [85].

Ethanol has been shown to increase antioxidant enzymes such as superoxide dismutase and catalase in myocytes [86]. A recent in vivo mouse study revealed that activation of ALDH2 by acute ethanol exposure is involved in the detoxification of toxic 
aldehyde such as 4-HNE which mediates oxidative damage through activated $\varepsilon$-PKC translocated to mitochondria [78].

NO increases ventricular function and serves as a signaling molecule at low concentrations $[87,88]$, but triggers inflammation and suppresses contractile function at high concentrations [89]. Endothelial nitric oxide synthase (eNOS) is important for regulating basal vascular tone and blood pressure [90,91]. Cardiac myocytes also express eNOS [92] which plays a role in regulating myocardial contractile function and oxygen consumption [93] [94]. Knockout mice lacking eNOS suffer larger infarcts than wild type after ischemia [95]. eNOS overexpression in mice attenuates myocardial reperfusion injury [96]. Ethanol has been shown to increase NO production through modulation of eNOS expression [97]. Abou-Agag et al. reported that moderate ethanol consumption for 8 weeks (defined as $9 \%$ of total caloric intake) enhanced maximum vascular relaxation and increased plasma NO production concomitant with increase in eNOS protein in the vascular endothelium. In contrast, heavy ethanol consumption (defined as $\sim 36 \%$ of total caloric intake) reduced maximum vascular relaxation [98]. We have recently demonstrated that ethanol preconditioning can be enhanced by administration of the volatile anesthetics, sevoflurane before ischemia through upregulation of eNOS by ethanol [99].

We have recently examined how long ethanol's cardioprotection persists after abstention and whether inducible NOS (iNOS) and/or eNOS play a role in this continued cardioprotection. Guinea pigs received 5\% ethanol in their drinking water for 8 weeks. Isolated hearts were subjected to $30 \mathrm{~min}$ ischemia and $120 \mathrm{~min}$ reperfusion at $0,4,7$ and 14 days after abstention. Contractile recovery after ischemia-reperfusion was significantly improved at 0,4 and 7 , but not 14 days of abstention, compared to controls. Western blot 
analysis and immunohistochemistry demonstrated upregulation of eNOS expression up to 7 days, but not 14 days abstention. Expression of iNOS declined at 0 day. These data suggest that chronic cardioprotection against ischemia-reperfusion injury by regular ethanol consumption persists for at least 7 days after abstention. Increased eNOS activity plays a role in this persistent cardioprotection [100].

Decreased expression of iNOS in ethanol treated hearts might be due to attenuation of inflammation. Growing evidence suggests that anti-inflammatory effects of moderate ethanol consumption not only reduce the incidence of coronary artery disease [101] but also attenuate inflammation after ischemia-reperfusion [102]. Previous experiments suggest that inflammation plays a role in ischemia-reperfusion injury [103]. NO derived from iNOS mediates cardiac dysfunction by inducing production of pro-inflammatory cytokines [104]. Cytokines such as IL-1, IL-6, and TNF- $\alpha$ are upregulated rapidly in response to myocardial ischemia [105]. Yamaguchi et al. found that the late phase of ethanol cardiac preconditioning correlated with reduced leukocyte-endothelial cell adhesive interactions, suggesting an anti-inflammatory effect [106]. This effect appears dependent on PKC [107]. eNOS was shown to be essential for the anti-inflammatory effects of the late phase of ethanol preconditioning [108].

Recently, prevention of mitochondrial permeability transition pore (mPTP) opening by inhibition of glycogen synthase kinase $3 \beta$ (GSK-3 $\beta$ ) has been implicated in ischemic preconditioning [109]. Irreversible mPTP opening abolishes the mitochondrial membrane potential, disabling the mitochondria ATP production. GSK-3 $\beta$ is a substrate of multiple prosurvival protein kinases, including Akt, $\varepsilon$-PKC, extracellular signal-regulated kinase 1/2 (ERK) and protein kinase G. Inhibition through phosphorylation of GSK-3 $\beta$ by PI3/Akt 
signaling is a key event for prevention of mPTP opening, increasing cell survival [110]. Zhong et al. reported that mice fed $18 \%$ ethanol in their drinking water for 12 weeks demonstrated sustained translocation of $\varepsilon$-PKC and increased expression of Akt [111]. Recently, Zhou et al. demonstrated that $10-500 \mu \mathrm{M}$ (light) but not $1 \mathrm{mM}$ (heavy) ethanol

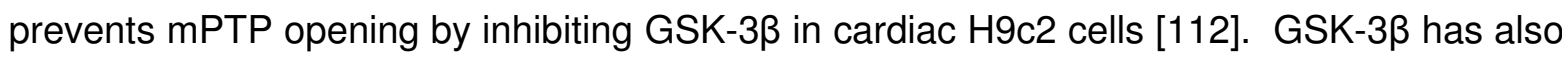
been shown to play a role in apoptosis [113]. Active GSK-3 $\beta$ facilitates apoptosis induced through mitochondrial pathway, whereas it suppresses pro-apoptotic signaling from death receptors such as Fas, TNF-R1 and DR4,5 [113-115]. It remains unclear whether chronic alcohol consumption affects mitochondrial apoptotic protein, such as Bax, Bad and Bcl2 by

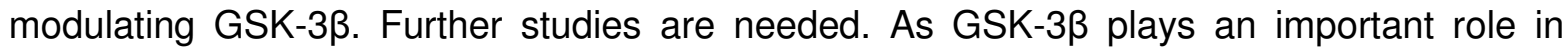
cardiomyocyte death, manipulation of this protein kinase by ethanol may help in developing strategy for cardioprotection. The role of other protein kinases such as protein tyrosine kinase and mitogen-activated protein kinase (MAPK) in cardioprotection by regular ethanol consumption has not been established. Both kinases have been implicated in ischemic preconditioning [116-118]. A study demonstrated that the infarct size limiting effect of acute ethanol exposure was abolished by genistein (non-selective protein tyrosine kinase) in isolated rabbit hearts [119]. MAPK such as p38 MAPK, ERK and c-Jun NH2-terminal (JNK) have been also implicated in ischemic preconditioning [120]. Sanada et al. reported that transient p38 MAPK activation during preconditioning is a trigger for IPC [118]. Involvement of ERK and JNK in cardioprotection by ethanol remains unclear. One study demonstrated that acute moderate ethanol exposure (4 or $8 \mathrm{mM}$ ), but not heavy exposure, to vascular smooth muscle stimulated ERK activity which was blocked by PKC inhibitor [121]. In contrast, Churchill et al. reported that intraperitoneal injection of ethanol $(0.5 \mathrm{~g} / \mathrm{kg})$ in mice 60 min prior to ischemia-reperfusion reduced phosphorylation of ERK and JNK compared with 
control hearts [78]. Further study will be needed to elucidate involvement of ERK and JNK in cardioprotection by regular ethanol consumption.

\section{Cardioprotection by Chronic Ethanol Consumption: dose, duration and washout}

A cardioprotection by regular ethanol consumption is dependent on the time and duration of ethanol exposure. The definition of one ethanol drink varies remarkably by publication and countries. The terms such as light, moderate and heavy drinking are vague. For example, one drink is $0.5 \mathrm{fl} \mathrm{oz}$ or $12 \mathrm{~g}$ of ethanol in USA, $8 \mathrm{~g}$ in England and $20-24 \mathrm{~g}$ in Japan. According to Dietary Guidelines for Americans, moderate drinking is no more than 1 drink ( $12 \mathrm{~g}$ of ethanol) per day for women and no more than 2 drinks ( $24 \mathrm{~g}$ of ethanol) per day for men [122]. In experimental studies, the concentration of ethanol varies significantly. There are differences in dose and duration of ethanol consumption, mode of administration, units used to express the amount of ethanol ( $\mathrm{mg} / \mathrm{dl}$, $\mathrm{mM}$ etc.). Serum levels of ethanol fluctuate depending on the time of blood sampling as animals do not drink constantly through the day. Further, elimination rates of ethanol are different among species. For example, guinea pigs eliminate ethanol 50 to $60 \%$ faster (2.59 micromol/g liver/min) [123] than humans (1.63-1.76 $\mathrm{micromol} / \mathrm{g}$ liver/min) [124]. We fed guinea pigs a nutritionally supplemented liquid diet containing $15 \%$ ethanol-derived calories for 8 weeks [58]. This approximates the upper limits of moderate ethanol consumption in human $45 \mathrm{~g}$ of ethanol/day, at $7 \mathrm{kcal} / \mathrm{g}$ ethanol, results in $\sim 15 \%$ ethanol-derived calories in a $2000 \mathrm{kcal}$ diet) [125]. In this study, serum ethanol levels at 9-11am were $10 \pm 2 \mathrm{mg} / \mathrm{dl}$ (about $2.2 \mathrm{mM}$ ). The duration of treatment is also important. In our early studies of ethanol preconditioning, 
the duration required for cardioprotection was at least for 3 weeks with $10 \%$ ethanol in the drinking water of guinea pig. Treatment for 3 weeks with $2.5 \%$ or $5 \%$ ethanol did not induce full protection [17]. Rat hearts treated with ethanol dosed at $9 \%(v / v)$ for 7 weeks [60] or $18 \%(\mathrm{v} / \mathrm{v})$ for 10 months [81] both showed a cardioprotection after ischemia-reperfusion, with average serum ethanol levels of $1.7 \pm 0.1 \mathrm{mg} / \mathrm{dl}$ (about $0.4 \mathrm{mM}$ ) or $15.4 \pm 0.6 \mathrm{mg} / \mathrm{dl}$ (about $3 \mathrm{mM}$ ), respectively. Pagel et al. fed dogs with ethanol $(1.5 \mathrm{~g} / \mathrm{day})$ mixed with dry food twice per day for 12 weeks. Average serum ethanol concentration was $11 \mathrm{mM}$ [61]. Chen et al. used $10 \mathrm{mM}$ ethanol to induce cardioprotection by acute ethanol exposure in isolated perfused rat hearts before and throughout ischemia [126]. However, the presence of ethanol during ischemia seems to have antiprotective effects in rabbit hearts. Krenz et al. demonstrated that ethanol levels of between 6 and $12 \mathrm{mM}$ during ischemia abolished the protective effect of acute ethanol exposure in in vivo rabbit hearts [127]. They also found that ethanol at concentrations of $5-50 \mathrm{mM}$ reduced infarct size if washed out before ischemia. They determined that a threshold ethanol level for cardioprotection in rabbit was approximately $3 \mathrm{mM}$. In previous studies from our laboratory, whether ethanol was withdrawn 12-16 $\mathrm{h}$ before ischemia (wash out) or ethanol was not withdrawn from the drinking water before sacrifice (serum ethanol levels at the time of sacrifice were $2.7 \pm 0.5$ $\mathrm{mM}$ in guinea pigs receiving $2.5 \%$ ethanol), cardioprotection from ischemia-reperfusion injury was observed $[17,99]$.

Thus, the serum ethanol levels can vary remarkably depending on dosing, time of blood sampling, and species. 


\section{Clinical Perspective}

Data presented in this review would suggest that ethanol can be used as a potential cardioprotective therapeutic agent. However, the negative effects of excessive drinking must be taken into account. Heavy drinking is one of the leading preventable causes of death worldwide [128]. A recent study has shown that one in every 25 deaths worldwide and $5 \%$ of global disability-adjusted life-years are attributable to ethanol consumption [129]. Heavy drinkers have a much higher rate of morbidity and mortality that overcomes any potential benefit against ischemic heart disease. Yet, epidemiological evidence suggests that moderate drinking reduces the risk of ischemic heart disease. Further, animal data suggest that regular ethanol consumption protects against ischemia-reperfusion injury; a possible mechanism accounting for increased survival after myocardial infarction in moderate drinkers versus abstainers. And as stated above, we found that the infarct size limiting effect by regular ethanol consumption persists for at least 7 days after abstention. Nevertheless, it would be inappropriate to recommend drinking to patients to protect their heart. While ethanol itself cannot be recommended as a therapeutic agent, understanding the mechanisms underlying its cardioprotective effects could lead to safer therapies.

It is important to note that recent studies demonstrate acute (as opposed to chronic) ethanol exposure fails to exert a cardioprotective effect during ischemia-reperfusion [127]. A recent randomized, prospective study in human found that administration of a moderate dose of ethanol abolished ischemic preconditioning and was associated with worsening subsequent ischemia [130].

Elucidating the mechanism underlying ethanol cardioprotection may help in the development of cardioprotective therapies in the perioperative setting. We recently found 
that the infarct size limiting effect by regular ethanol consumption is enhanced by sevoflurane [99]. Because anesthetics can be administrated with relatively low toxicity, elucidating the interaction between ethanol and volatile anesthetic-induced preconditioning and the underlying mechanisms may be beneficial for reducing perioperative myocardial ischemia-reperfusion injury. Growing evidence that long-term ethanol consumption mimics ischemic preconditioning opens a new avenue for developing novel therapies to improve outcomes in patient at risk for myocardial infarction. 


\section{ACKNOWLEDGEMENTS}

This study was supported by Grant-in-Aid for Scientific Research (C) 20592382 from the Ministry of Education, Culture, Sports, Science and Technology of Japan (Masami Miyamae) (Tokyo, Japan), "High-Tech Research Center" Project for Private Universities: matching fund subsidy, 2007-2011 from the Ministry of Education, Culture, Sports, Science and Technology of Japan (Naochika Domae) (Tokyo, Japan). 


\section{References}

[1] Klatsky AL, Armstrong MA, Friedman GD. Risk of cardiovascular mortality in alcohol drinkers, ex-drinkers and nondrinkers. Am J Cardiol 1990; 66: 1237-42.

[2] Rimm EB, Giovannucci EL, Willett WC et al. Prospective study of alcohol consumption and risk of coronary disease in men. Lancet 1991; 338: 464-8.

[3] Fuchs CS, Stampfer MJ, Colditz GA et al. Alcohol consumption and mortality among women. N Engl J Med 1995; 332: 1245-50.

[4] Thun MJ, Peto R, Lopez AD et al. Alcohol consumption and mortality among middleaged and elderly U.S. adults. N Engl J Med 1997; 337: 1705-14.

[5] Collins MA, Neafsey EJ, Mukamal KJ et al. Alcohol in moderation, cardioprotection, and neuroprotection: epidemiological considerations and mechanistic studies. Alcohol Clin Exp Res 2009; 33: 206-19.

[6] Flesch M, Rosenkranz S, Erdmann E, Bohm M. Alcohol and the risk of myocardial infarction. Basic Res Cardiol 2001; 96: 128-35.

[7] Mukamal KJ, Chung H, Jenny NS et al. Alcohol consumption and risk of coronary heart disease in older adults: the Cardiovascular Health Study. J Am Geriatr Soc 2006; 54: 30-7.

[8] Gaziano JM, Buring JE, Breslow JL et al. Moderate alcohol intake, increased levels of high-density lipoprotein and its subfractions, and decreased risk of myocardial infarction. N Engl J Med 1993; 329: 1829-34.

[9] Pikaar NA, Wedel M, van der Beek EJ et al. Effects of moderate alcohol consumption on platelet aggregation, fibrinolysis, and blood lipids. Metabolism 1987; 36: 538-43. 
[10] Ridker PM, Vaughan DE, Stampfer MJ, Glynn RJ, Hennekens CH. Association of moderate alcohol consumption and plasma concentration of endogenous tissue-type plasminogen activator. Jama 1994; 272: 929-33.

[11] Marugame T, Yamamoto S, Yoshimi I et al. Patterns of alcohol drinking and allcause mortality: results from a large-scale population-based cohort study in Japan. Am J Epidemiol 2007; 165: 1039-46.

[12] Muntwyler J, Hennekens $\mathrm{CH}$, Buring JE, Gaziano JM. Mortality and light to moderate alcohol consumption after myocardial infarction. Lancet 1998; 352: $1882-$ 5.

[13] Mukamal KJ, Maclure M, Muller JE, Sherwood JB, Mittleman MA. Prior alcohol consumption and mortality following acute myocardial infarction. Jama $2001 ; 285$ : 1965-70.

[14] de Lorgeril M, Salen P, Martin JL et al. Wine drinking and risks of cardiovascular complications after recent acute myocardial infarction. Circulation 2002; 106: 14659.

[15] Korthuis RJ. Introduction to the special topics issue on alcohol and cardioprotection. Pathophysiology 2004; 10: 81-2.

[16] Janszky I, Ljung R, Ahnve S et al. Alcohol and long-term prognosis after a first acute myocardial infarction: the SHEEP study. Eur Heart J 2008; 29: 45-53.

[17] Miyamae M, Diamond I, Weiner MW, Camacho SA, Figueredo VM. Regular alcohol consumption mimics cardiac preconditioning by protecting against ischemiareperfusion injury. Proc Natl Acad Sci U S A 1997; 94: 3235-9. 
[18] McDonough $\mathrm{KH}$. Chronic alcohol consumption causes accelerated myocardial preconditioning to ischemia-reperfusion injury. Alcohol Clin Exp Res 1997; 21: 86973.

[19] Murry CE, Jennings RB, Reimer KA. Preconditioning with ischemia: a delay of lethal cell injury in ischemic myocardium. Circulation 1986; 74: 1124-36.

[20] Rimm EB, Williams P, Fosher K, Criqui M, Stampfer MJ. Moderate alcohol intake and lower risk of coronary heart disease: meta-analysis of effects on lipids and haemostatic factors. Bmj 1999; 319: 1523-8.

[21] Lucas DL, Brown RA, Wassef M, Giles TD. Alcohol and the cardiovascular system research challenges and opportunities. J Am Coll Cardiol 2005; 45: 1916-24.

[22] Taskinen MR, Nikkila EA, Valimaki $M$ et al. Alcohol-induced changes in serum lipoproteins and in their metabolism. Am Heart J 1987; 113: 458-64.

[23] Fromenty B, Vadrot $\mathrm{N}$, Massart $\mathrm{J}$ et al. Chronic ethanol consumption lessens the gain of body weight, liver triglycerides, and diabetes in obese ob/ob mice. $J$ Pharmacol Exp Ther 2009; 331: 23-34.

[24] De Oliveira ESER, Foster D, McGee Harper M et al. Alcohol consumption raises HDL cholesterol levels by increasing the transport rate of apolipoproteins A-I and AII. Circulation 2000; 102: 2347-52.

[25] Mukamal KJ, Jensen MK, Gronbaek $M$ et al. Drinking frequency, mediating biomarkers, and risk of myocardial infarction in women and men. Circulation 2005; 112: 1406-13.

[26] Beulens JW, Rimm EB, Ascherio A et al. Alcohol consumption and risk for coronary heart disease among men with hypertension. Ann Intern Med 2007; 146: 10-9. 
[27] Criqui MH, Cowan LD, Tyroler HA et al. Lipoproteins as mediators for the effects of alcohol consumption and cigarette smoking on cardiovascular mortality: results form the Lipid Research Clinics Follow-up Study. Am J Epidemiol 1987; 126: 629-37.

[28] Langer RD, Criqui MH, Reed DM. Lipoproteins and blood pressure as biological pathways for effect of moderate alcohol consumption on coronary heart disease. Circulation 1992; 85: 910-5.

[29] Belleville J. The French paradox: possible involvement of ethanol in the protective effect against cardiovascular diseases. Nutrition 2002; 18: 173-7.

[30] Booyse FM, Pan W, Grenett HE et al. Mechanism by which alcohol and wine polyphenols affect coronary heart disease risk. Ann Epidemiol 2007; 17: S24-31.

[31] Miura Y, Hosono M, Oyamada C et al. Dietary isohumulones, the bitter components of beer, raise plasma HDL-cholesterol levels and reduce liver cholesterol and triacylglycerol contents similar to PPARalpha activations in C57BL/6 mice. Br J Nutr 2005; 93: 559-67.

[32] Rao MN, Marmillot P, Gong M et al. Light, but not heavy alcohol drinking, stimulates paraoxonase by upregulating liver mRNA in rats and humans. Metabolism 2003; 52: 1287-94.

[33] van der Gaag MS, van Tol A, Scheek LM et al. Daily moderate alcohol consumption increases serum paraoxonase activity; a diet-controlled, randomised intervention study in middle-aged men. Atherosclerosis 1999; 147: 405-10.

[34] Durrington PN, Mackness B, Mackness MI. Paraoxonase and atherosclerosis. Arterioscler Thromb Vasc Biol 2001; 21: 473-80. 
[35] Schafer C, Parlesak A, Eckoldt $J$ et al. Beyond HDL-cholesterol increase: phospholipid enrichment and shift from HDL3 to HDL2 in alcohol consumers. J Lipid Res 2007; 48: 1550-8.

[36] Imhof A, Froehlich $\mathrm{M}$, Brenner $\mathrm{H}$ et al. Effect of alcohol consumption on systemic markers of inflammation. Lancet 2001; 357: 763-7.

[37] Sacanella E, Estruch R. The effect of alcohol consumption on endothelial adhesion molecule expression. Addict Biol 2003; 8: 371-8.

[38] Albert MA, Glynn RJ, Ridker PM. Plasma concentration of C-reactive protein and the calculated Framingham Coronary Heart Disease Risk Score. Circulation 2003; 108: $161-5$.

[39] Pai JK, Hankinson SE, Thadhani R et al. Moderate alcohol consumption and lower levels of inflammatory markers in US men and women. Atherosclerosis 2006; 186 : 113-20.

[40] Salem RO, Laposata M. Effects of alcohol on hemostasis. Am J Clin Pathol 2005; 123 Suppl: S96-105.

[41] Bell RA, Mayer-Davis EJ, Martin MA, D'Agostino RB, Jr., Haffner SM. Associations between alcohol consumption and insulin sensitivity and cardiovascular disease risk factors: the Insulin Resistance and Atherosclerosis Study. Diabetes Care 2000; 23: 1630-6.

[42] Djousse L, Pankow JS, Arnett DK et al. Alcohol consumption and plasminogen activator inhibitor type 1: the National Heart, Lung, and Blood Institute Family Heart Study. Am Heart J 2000; 139: 704-9. 
[43] Mukamal KJ, Jadhav PP, D'Agostino RB et al. Alcohol consumption and hemostatic factors: analysis of the Framingham Offspring cohort. Circulation 2001; 104: 136773.

[44] van de Wiel A, van Golde PM, Kraaijenhagen RJ et al. Acute inhibitory effect of alcohol on fibrinolysis. Eur J Clin Invest 2001; 31: 164-70.

[45] Kumari M, Marmot M, Brunner E. Social determinants of von willebrand factor: the Whitehall II study. Arterioscler Thromb Vasc Biol 2000; 20: 1842-7.

[46] Bau PF, Bau CH, Rosito GA, Manfroi WC, Fuchs FD. Alcohol consumption, cardiovascular health, and endothelial function markers. Alcohol 2007; 41: 479-88.

[47] Lamas S, Perez-Sala D, Moncada S. Nitric oxide: from discovery to the clinic. Trends Pharmacol Sci 1998; 19: 436-8.

[48] Ross R. The pathogenesis of atherosclerosis: a perspective for the 1990s. Nature 1993; 362: 801-9.

[49] Furuya DT, Binsack R, Machado UF. Low ethanol consumption increases insulin sensitivity in Wistar rats. Braz J Med Biol Res 2003; 36: 125-30.

[50] Freiberg MS, Cabral HJ, Heeren TC, Vasan RS, Curtis Ellison R. Alcohol consumption and the prevalence of the Metabolic Syndrome in the US.: a crosssectional analysis of data from the Third National Health and Nutrition Examination Survey. Diabetes Care 2004; 27: 2954-9.

[51] Ness AR, Powles JW. Fruit and vegetables, and cardiovascular disease: a review. Int J Epidemiol 1997; 26: 1-13.

[52] Law MR, Morris JK. By how much does fruit and vegetable consumption reduce the risk of ischaemic heart disease? Eur J Clin Nutr 1998; 52: 549-56. 
[53] Covas Ml, Konstantinidou V, Fito M. Olive oil and cardiovascular health. J Cardiovasc Pharmacol 2009; 54: 477-82.

[54] Pedersen JO, Heitmann BL, Schnohr P, Gronbaek M. The combined influence of leisure-time physical activity and weekly alcohol intake on fatal ischaemic heart disease and all-cause mortality. Eur Heart J 2008; 29: 204-12.

[55] Bosron WF, Lumeng L, Li TK. Genetic polymorphism of enzymes of alcohol metabolism and susceptibility to alcoholic liver disease. Mol Aspects Med 1988; 10: 147-58.

[56] Li TK. Pharmacogenetics of responses to alcohol and genes that influence alcohol drinking. J Stud Alcohol 2000; 61: 5-12.

[57] Miyamae M, Camacho SA, Zhou HZ, Diamond I, Figueredo VM. Alcohol consumption reduces ischemia-reperfusion injury by species-specific signaling in guinea pigs and rats. Am J Physiol 1998; 275: H50-6.

[58] Miyamae M, Rodriguez MM, Camacho SA et al. Activation of epsilon protein kinase C correlates with a cardioprotective effect of regular ethanol consumption. Proc Natl Acad Sci U S A 1998; 95: 8262-7.

[59] Ping P, Zhang J, Qiu $Y$ et al. Ischemic preconditioning induces selective translocation of protein kinase $C$ isoforms $\varepsilon$ and $\eta$ in the heart of conscious rabbits without subcellular redistribution of total protein kinase C activity. Circ Res 1997; 81: 404-14.

[60] Guiraud A, de Lorgeril M, Boucher F et al. Cardioprotective effect of chronic low dose ethanol drinking: insights into the concept of ethanol preconditioning. $\mathrm{J} \mathrm{Mol}$ Cell Cardiol 2004; 36: 561-6. 
[61] Pagel PS, Toller WG, Gross ER et al. K(ATP) channels mediate the beneficial effects of chronic ethanol ingestion. Am J Physiol Heart Circ Physiol 2000; 279: H2574-9.

[62] Dow JS, Hale SL, Kloner RA. Can moderate alcohol intake limit the size of myocardial infarction? J Cardiovasc Pharmacol 2001; 37: 662-7.

[63] Gibson BT, Ong JH, Starnes JW, Farrar RP. Effects of chronic moderate and heavy ethanol consumption on myocardial recovery from ischemia. Alcohol Clin Exp Res 1998; 22: 2086-92.

[64] Diamond I, Gordon AS. The role of adenosine in mediating cellular and molecular responses to ethanol. Exs $1994 ; 71: 175-83$.

[65] Diamond I, Gordon AS. Cellular and molecular neuroscience of alcoholism. Physiol Rev 1997; 77: 1-20.

[66] Nagy LE, Diamond I, Casso DJ, Franklin C, Gordon AS. Ethanol increases extracellular adenosine by inhibiting adenosine uptake via the nucleoside transporter. J Biol Chem 1990; 265: 1946-51.

[67] Van Winkle DM, Chien GL, Wolff RA et al. Cardioprotection provided by adenosine receptor activation is abolished by blockade of the KATP channel. Am J Physiol 1994; 266: H829-39.

[68] Liu GS, Thornton J, Van Winkle DM et al. Protection against infarction afforded by preconditioning is mediated by $\mathrm{A} 1$ adenosine receptors in rabbit heart. Circulation $1991 ; 84: 350-6$.

[69] Auchampach JA, Gross GJ. Adenosine A1 receptors, KATP channels, and ischemic preconditioning in dogs. Am J Physiol 1993; 264: H1327-36. 
[70] Kitakaze M, Hori M, Takashima $S$ et al. Ischemic preconditioning increases adenosine release and 5'-nucleotidase activity during myocardial ischemia and reperfusion in dogs. Implications for myocardial salvage. Circulation 1993; 87: 20815.

[71] Walker DM, Walker JM, Pugsley WB, Pattison CW, Yellon DM. Preconditioning in isolated superfused human muscle. J Mol Cell Cardiol 1995; 27: 1349-57.

[72] Nagy LE, DeSilva SE. Adenosine A1 receptors mediate chronic ethanol-induced increases in receptor-stimulated cyclic AMP in cultured hepatocytes. Biochem $\mathrm{J}$ 1994; 304 ( Pt 1): 205-10.

[73] Mochly-Rosen D, Chang FH, Cheever L et al. Chronic ethanol causes heterologous desensitization of receptors by reducing alpha s messenger RNA. Nature 1988; 333: 848-50.

[74] Gordon AS, Collier K, Diamond I. Ethanol regulation of adenosine receptorstimulated cAMP levels in a clonal neural cell line: an in vitro model of cellular tolerance to ethanol. Proc Natl Acad Sci U S A 1986; 83: 2105-8.

[75] Miyamae M, Domae N, Zhou HZ et al. Phospholipase C activation is required for cardioprotection by ethanol consumption. Exp Clin Cardiol 2003; 8: 184-188.

[76] Churchill EN, Disatnik MH, Budas GR, Mochly-Rosen D. Ethanol for cardiac ischemia: the role of protein kinase c. Ther Adv Cardiovasc Dis 2008; 2: 469-83.

[77] Inagaki K, Mochly-Rosen D. $\delta P K C$-mediated activation of $\varepsilon P K C$ in ethanol-induced cardiac protection from ischemia. J Mol Cell Cardiol 2005; 39: 203-11.

[78] Churchill EN, Disatnik MH, Mochly-Rosen D. Time-dependent and ethanol-induced cardiac protection from ischemia mediated by mitochondrial translocation of 
varepsilonPKC and activation of aldehyde dehydrogenase 2. J Mol Cell Cardiol 2009; 46: 278-84.

[79] Aizawa K, Turner LA, Weihrauch D, Bosnjak ZJ, Kwok WM. Protein kinase Cepsilon primes the cardiac sarcolemmal adenosine triphosphate-sensitive potassium channel to modulation by isoflurane. Anesthesiology 2004; 101: 381-9.

[80] Costa AD, Garlid KD, West IC et al. Protein kinase G transmits the cardioprotective signal from cytosol to mitochondria. Circ Res 2005; 97: 329-36.

[81] Zhu P, Zhou HZ, Gray MO. Chronic ethanol-induced myocardial protection requires activation of mitochondrial KATP channels. J Mol Cell Cardiol 2000; 32: 2091-5.

[82] Pagel PS, Krolikowski JG, Kehl F et al. The role of mitochondrial and sarcolemmal KATP channels in canine ethanol-induced preconditioning in vivo. Anesth Analg 2002; 94: 841-8.

[83] Sasaki N, Sato T, Ohler A, O'Rourke B, Marban E. Activation of mitochondrial ATPdependent potassium channels by nitric oxide. Circulation 2000; 101: 439-45.

[84] Andrukhiv A, Costa AD, West IC, Garlid KD. Opening mitochondrial KATP increases superoxide generation from complex I of the electron transport chain. Am J Physiol Heart Circ Physiol 2006; 291: H2067-74.

[85] Costa AD, Garlid KD. Intramitochondrial signaling: interactions among mitoKATP, PKC- $\varepsilon$, ROS, and MPT. Am J Physiol Heart Circ Physiol 2008; 295: H874-82.

[86] Edes I, Toszegi A, Csanady M, Bozoky B. Myocardial lipid peroxidation in rats after chronic alcohol ingestion and the effects of different antioxidants. Cardiovasc Res 1986; 20: 542-8.

[87] Rassaf T, Poll LW, Brouzos P et al. Positive effects of nitric oxide on left ventricular function in humans. Eur Heart J 2006; 27: 1699-705. 
[88] Penna C, Rastaldo R, Mancardi D et al. Post-conditioning induced cardioprotection requires signaling through a redox-sensitive mechanism, mitochondrial ATPsensitive $K+$ channel and protein kinase C activation. Basic Res Cardiol 2006; 101: 180-9.

[89] Schulz R, Kelm M, Heusch G. Nitric oxide in myocardial ischemia/reperfusion injury. Cardiovasc Res 2004; 61: 402-13.

[90] Patel RP, McAndrew J, Sellak $\mathrm{H}$ et al. Biological aspects of reactive nitrogen species. Biochim Biophys Acta 1999; 1411: 385-400.

[91] Radomski MW, Moncada S. Regulation of vascular homeostasis by nitric oxide. Thromb Haemost 1993; 70: 36-41.

[92] Balligand JL, Kobzik L, Han X et al. Nitric oxide-dependent parasympathetic signaling is due to activation of constitutive endothelial (type III) nitric oxide synthase in cardiac myocytes. J Biol Chem 1995; 270: 14582-6.

[93] Kojda G, Kottenberg K. Regulation of basal myocardial function by NO. Cardiovasc Res 1999; 41: 514-23.

[94] Heusch G, Post H, Michel MC, Kelm M, Schulz R. Endogenous nitric oxide and myocardial adaptation to ischemia. Circ Res 2000; 87: 146-52.

[95] Sumeray MS, Rees DD, Yellon DM. Infarct size and nitric oxide synthase in murine myocardium. J Mol Cell Cardiol 2000; 32: 35-42.

[96] Jones SP, Greer JJ, Kakkar AK et al. Endothelial nitric oxide synthase overexpression attenuates myocardial reperfusion injury. Am J Physiol Heart Circ Physiol 2004; 286: H276-82. 
[97] Venkov CD, Myers PR, Tanner MA, Su M, DE V. Ethanol increases endothelial nitric oxide production through modulation of nitric oxide synthase expression. Thromb Haemost 1999; 81: 638-642.

[98] Abou-Agag LH, Khoo NK, Binsack R et al. Evidence of cardiovascular protection by moderate alcohol: role of nitric oxide. Free Radic Biol Med 2005; 39: 540-8.

[99] Kaneda K, Miyamae M, Sugioka S et al. Sevoflurane enhances ethanol-induced cardiac preconditioning through modulation of protein kinase $\mathrm{C}$, mitochondrial KATP channels, and nitric oxide synthase, in guinea pig hearts. Anesth Analg 2008; 106: 9-16.

[100] Kaneda K, Miyamae M, Sugioka S et al. Persistent Cardioprotection by Regular Ethanol Consumption After Abstention Depends on eNOS but not iNOS Activity After Reperfusion. . Circulation 2008; 118: 3889(S498).

[101] Volpato S, Pahor M, Ferrucci L et al. Relationship of alcohol intake with inflammatory markers and plasminogen activator inhibitor-1 in well-functioning older adults: the Health, Aging, and Body Composition study. Circulation 2004; 109: 60712.

[102] Chen Y, Davis-Gorman G, Watson RR, McDonagh PF. Chronic ethanol consumption modulates myocardial ischaemia-reperfusion injury in murine AIDS. Alcohol Alcohol 2003; 38: 18-24.

[103] Torre-Amione G, Kapadia S, Lee $\mathrm{J}$ et al. Expression and functional significance of tumor necrosis factor receptors in human myocardium. Circulation 1995; 92: 148793.

[104] Csont T, Viappiani S, Sawicka $J$ et al. The involvement of superoxide and iNOSderived NO in cardiac dysfunction induced by pro-inflammatory cytokines. J Mol Cell Cardiol 2005; 39: 833-40. 
[105] Nian M, Lee P, Khaper N, Liu P. Inflammatory cytokines and postmyocardial infarction remodeling. Circ Res 2004; 94: 1543-53.

[106] Yamaguchi T, Dayton C, Shigematsu T et al. Preconditioning with ethanol prevents postischemic leukocyte-endothelial cell adhesive interactions. Am J Physiol Heart Circ Physiol 2002; 283: H1019-30.

[107] Dayton C, Yamaguchi T, Kamada K, Carter P, Korthuis RJ. Antecedent ethanol ingestion prevents postischemic leukocyte adhesion and P-selectin expression by a protein kinase C-dependent mechanism. Dig Dis Sci 2005; 50: 684-90.

[108] Yamaguchi T, Kamada K, Dayton C et al. Role of eNOS-derived NO in the postischemic anti-inflammatory effects of antecedent ethanol ingestion in murine small intestine. Am J Physiol Heart Circ Physiol 2007; 292: H1435-42.

[109] Miura T, Miki T. GSK-3beta, a therapeutic target for cardiomyocyte protection. Circ J 2009; 73: 1184-92.

[110] Juhaszova M, Zorov DB, Kim SH et al. Glycogen synthase kinase-3beta mediates convergence of protection signaling to inhibit the mitochondrial permeability transition pore. J Clin Invest 2004; 113: 1535-49.

[111] Zhou HZ, Karliner JS, Gray MO. Moderate alcohol consumption induces sustained cardiac protection by activating PKC-epsilon and Akt. Am J Physiol Heart Circ Physiol 2002; 283: H165-74.

[112] Zhou K, Zhang L, Xi J, Tian W, Xu Z. Ethanol prevents oxidant-induced mitochondrial permeability transition pore opening in cardiac cells. Alcohol Alcohol 2009; 44: 20-4. 
[113] Liao X, Zhang L, Thrasher JB, Du J, Li B. Glycogen synthase kinase-3beta suppression eliminates tumor necrosis factor-related apoptosis-inducing ligand resistance in prostate cancer. Mol Cancer Ther 2003; 2: 1215-22.

[114] Song L, Zhou T, Jope RS. Lithium facilitates apoptotic signaling induced by activation of the Fas death domain-containing receptor. BMC Neurosci 2004; 5: 20.

[115] Rottmann S, Wang Y, Nasoff M, Deveraux QL, Quon KC. A TRAIL receptordependent synthetic lethal relationship between MYC activation and GSK3beta/FBW7 loss of function. Proc Natl Acad Sci U S A 2005; 102: 15195-200.

[116] Fryer RM, Schultz JE, Hsu AK, Gross GJ. Importance of PKC and tyrosine kinase in single or multiple cycles of preconditioning in rat hearts. Am J Physiol 1999; 276: H1229-35.

[117] Fryer RM, Pratt PF, Hsu AK, Gross GJ. Differential activation of extracellular signal regulated kinase isoforms in preconditioning and opioid-induced cardioprotection. $J$ Pharmacol Exp Ther 2001; 296: 642-9.

[118] Sanada S, Kitakaze M, Papst PJ et al. Role of phasic dynamism of p38 mitogenactivated protein kinase activation in ischemic preconditioning of the canine heart. Circ Res 2001; 88: 175-80.

[119] Krenz M, Baines CP, Heusch G, Downey JM, Cohen MV. Acute alcohol-induced protection against infarction in rabbit hearts: differences from and similarities to ischemic preconditioning. J Mol Cell Cardiol 2001; 33: 2015-22.

[120] Armstrong SC. Protein kinase activation and myocardial ischemia/reperfusion injury. Cardiovasc Res 2004; 61: 427-36. 
[121] Washington B, Mtshali C, Williams $S$ et al. Ethanol-induced mitogen activated protein kinase activity mediated through protein kinase C. Cell Mol Biol (Noisy-legrand) 2003; 49: 1351-6.

[122] US Department of Agriculture and US Department of Health and Human Service. Alcoholic beverages. In: Dietary Guidelines for Americans. Washington, DC. US Government Printing Office 2005: 43-6.

[123] Zahlten RN, Nejtek ME, Jacobson JC. Ethanol metabolism in guinea pig: in vivo ethanol elimination, alcohol dehydrogenase distribution, and subcellular localization of acetaldehyde dehydrogenase in liver. Arch Biochem Biophys 1981; 207: 371-9.

[124] Jones AW. Disappearance rate of ethanol from the blood of human subjects: implications in forensic toxicology. J Forensic Sci 1993; 38: 104-18.

[125] Stampfer MJ, Colditz GA, Willett WC, Speizer FE, Hennekens CH. A prospective study of moderate alcohol consumption and the risk of coronary disease and stroke in women. N Engl J Med 1988; 319: 267-73.

[126] Chen $\mathrm{CH}$, Gray MO, Mochly-Rosen D. Cardioprotection from ischemia by a brief exposure to physiological levels of ethanol: role of epsilon protein kinase C. Proc Natl Acad Sci U S A 1999; 96: 12784-9.

[127] Krenz M, Baines CP, Yang XM et al. Acute ethanol exposure fails to elicit preconditioning-like protection in in situ rabbit hearts because of its continued presence during ischemia. J Am Coll Cardiol 2001; 37: 601-7.

[128] Lopez AD, Mathers CD, Ezzati M, Jamison DT, Murray CJ. Global and regional burden of disease and risk factors, 2001: systematic analysis of population health data. Lancet 2006; 367: 1747-57. 
[129] Rehm J, Mathers C, Popova S et al. Global burden of disease and injury and economic cost attributable to alcohol use and alcohol-use disorders. Lancet 2009; 373: 2223-33.

[130] Niccoli G, Altamura L, Fabretti A et al. Ethanol abolishes ischemic preconditioning in humans. J Am Coll Cardiol 2008; 51: 271-5. 


\section{Figure Legends}

Figure 1: Dose effect and potential mechanisms for decreasing incidence of coronary heart disease by regular ethanol consumption

TNF-R1, R2=tumor necrosis factor-receptor 1, 2

Figure2. Hypothetical scheme for cardioprotection by ethanol against myocardial ischemiareperfusion injury

PLC=phospholipase C; PLD=phospholipase $D$; PKC=protein kinase C;

$\mathrm{PI3K}=$ phosphoinositide 3-kinase; $\mathrm{Akt}=$ protein kinase $\mathrm{B} ; \mathrm{GSK} 3 \beta=$ glycogen synthase kinase $3 \beta$; pGSK3 $\beta=$ phospho glycogen synthase kinase $3 \beta$; PTK=protein tyrosine kinase; ROS= reactive oxygen species; JNK=c-Jun $\mathrm{N}$-terminal kinase; $\mathrm{ERK}=$ extracellular signalregulated kinase; $\mathrm{MAPK}=$ mitogen-activated protein kinase; $\mathrm{ALDH} 2=$ aldehyde dehydrogenase 2; 4-HNE=4-hydroxy-2-nonenal; $\mathrm{Bcl} 2=\mathrm{B}$-cell leukemia 2 family protein; $\mathrm{Bad}=\mathrm{Bcl}$-antagonist of cell death; $\mathrm{mPTP}=$ mitochondrial permeability transition pore; $\mathrm{NO}=$ nitric oxide; eNOS=endothelial nitric oxide synthase.

Dotted line; to be elucidated.

\section{Table Legends}


Table 1; Isolated guinea pig hearts were subjected to $45 \mathrm{~min}$ of global ischemia and $48 \mathrm{~min}$ of reperfusion. Experiments were performed in hearts from guinea pigs consuming varying concentrations of ethanol in their drinking water for 3,6 , or 12 weeks. A group of hearts from animals not exposed to ethanol was subjected to ischemic preconditioning (PC). PC was elicited by $2 \mathrm{~min}$ of global ischemia and $5 \mathrm{~min}$ of reperfusion immediately before $45 \mathrm{~min}$ of ischemia. Creatine kinase release was measured in the coronary effluent during first 18 min of reperfusion (3-min intervals). Data are presented as mean \pm SEM.

Table 2; Effect of acute and chronic ethanol exposure to hearts against ischemiareperfusion injury 